\title{
Folias Galileu: o espectador em ato performativo
}

Folias Galileu: the spectator in performative act

\section{Giuliana Simões \\ Flávio Desgranges}

Giuliana Simões

Professora do Mestrado Profissional em Artes da Cena e da Pós-Graduação em

Direção Teatral da Escola Superior de Artes Célia Helena (ESCH)

Flávio Desgranges

Professor do Departamento de Artes Cênicas da UDESC

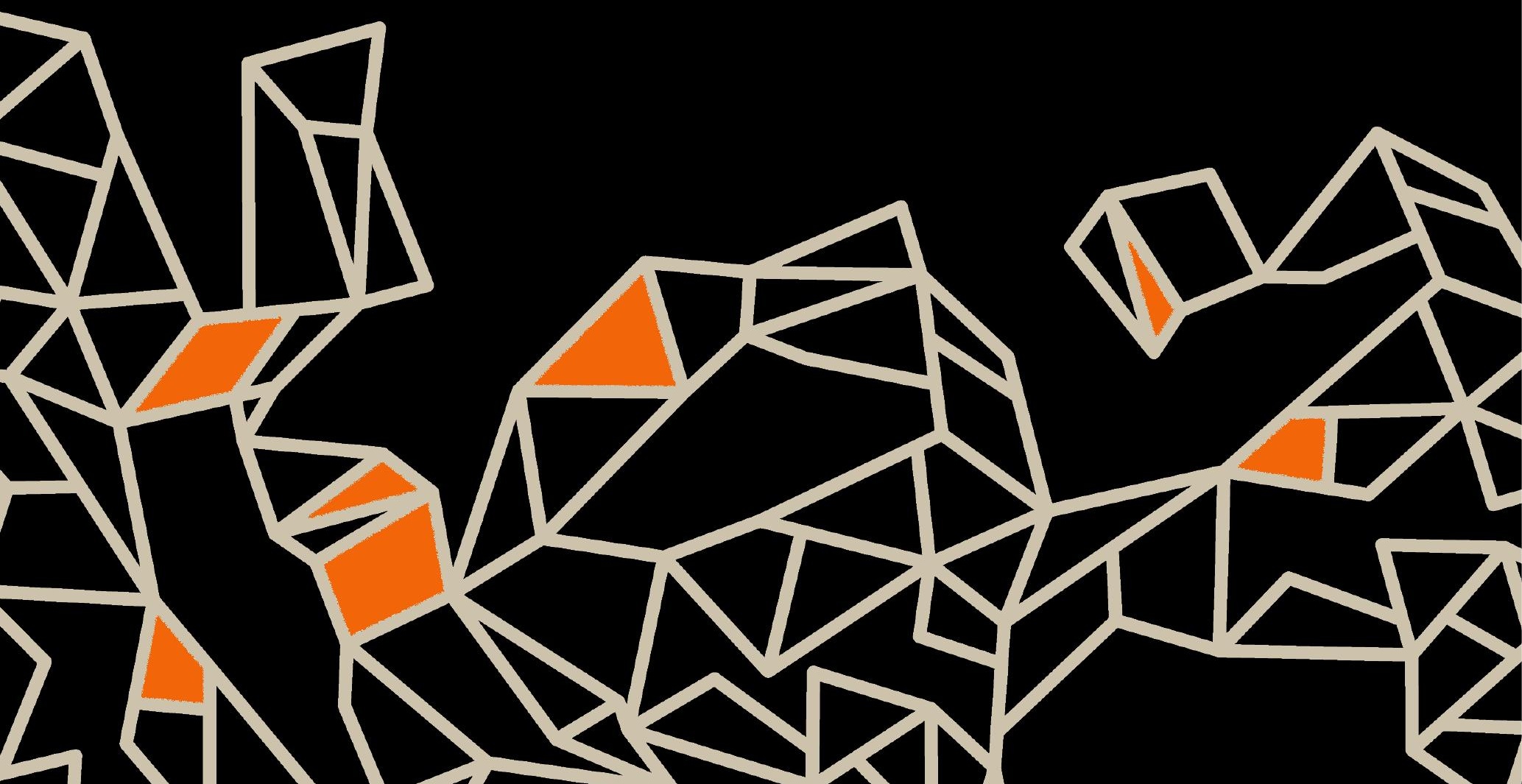




\section{Resumo}

O artigo trata da condição do público em proposições cênicas recentes, tendo em vista a perspectiva performativa do ato do espectador, que se volta menos para a tentativa de decifrar e interpretar o discurso cênico proferido, e se disponibiliza para outro modo de atuação, em que o sentido não é mais algo a ser explicado, mas um efeito a ser experimentado. Para realizar tal análise, debates performativos foram propostos a partir do espetáculo Folias Galileu, do Grupo Folias, buscando evidenciar o modo de produção do público em sua relação com o espetáculo e enunciar, em ato coletivo, uma poética dos espectadores.

Palavras-chave: Espectador, Efeito estético, Performatividade.

\section{Abstract}

The article deals with audience's condition in recent scenic propositions, taking into account the perfomative perspective of the spectator's act, which turns less to the attempt to decipher and interpret the delivered scenic speech and provides itself to another form of acting, in which the meaning is no longer something to be explained but an effect to be experimented. To perform such analysis, performative debates were proposed from the performance Folias Galileu, by Grupo Folias, seeking to demonstrate the audience's means of production in its relation to the performance and enunciate, in a collective act, a spectator's poetic.

Keywords: Spectator, Aesthetic effect, Performativity.

O acontecimento teatral, tal como se pode observar em parcela significativa das proposições cênicas recentes, solicita a instauração de outra lógica temporal, interrompendo o ritmo cotidiano, fundando um espaço para a necessária atuação do espectador. Para que se efetive como performativo - produtivo, criativo, artístico, enfim -, o ato do espectador solicita a instauração de um tempo que contrarie a lógica do cotidiano, que abra espaço para outro modo perceptivo, que nos afaste do conhecido, do usual, do esperado. O ato criador, "que enriquece o acontecimento existencial, é por princípio um ato extrarrítmico" (BAKHTIN, 1992, p. 133). A existência ritmizada se estabelece por sua gratuidade, ou regido por uma finalidade que não emana de 
uma escolha, de um julgamento, que não implica responsabilidade. O ritmo estético se constitui como violação do ritmo prosaico. "Não se trata de um ritmo complexo, mas de uma violação do ritmo, e uma violação tal que nós não podemos prever; se esta violação se torna um cânon, ela perderá a força que tinha como procedimento interruptivo" (CHKLOVSKI, 2001, p. 97).

O sentido de uma cena não se constitui como um dado prévio, estabelecido antes da leitura, algo pronto, fixo, atribuído desde sempre pelo artista, mas algo que se realiza na própria relação do espectador com a proposição cênica. Atribuir sentidos quer dizer estabelecê-los em relação a nós mesmos. O que solicita disponibilidade para se deixar atingir pelo objeto e se deixar atravessar pelo fato, pois uma cena não quer dizer nada que se resuma a um significado previsto de antemão, a que se queira ou se deva chegar. É justamente nessa indeterminação, como evento provido de finalidade mas sem um fim previamente instituído, que se organiza o acontecimento artístico. "Aí começa a inevitável pergunta: isto é arte? Não, senhoras e senhores, a arte é que é isto. Qualquer isto. Um isto problemático, reflexivo, que é necessário interrogar e decifrar" (BRITO, 2005, p. 75).

O que se espera do espectador, em sua relação com proposições artísticas que instaurem uma violação do ritmo cotidiano e evidenciem tal indeterminação na produção de sentidos, é que trate as palavras (e demais significantes) de sua língua como quem opera com uma língua estrangeira, que estranhe os sentidos comumente atribuídos a cada significante e se disponha a empreender experiências com a linguagem, a inventar outro modo operativo, subvertendo os regimes consensuais. $E$ recuse uma espécie de instantaneidade na emissão e na percepção das palavras, como se as significâncias fossem geradas por vontade própria; o que confere ao indivíduo a incômoda (ou, quem sabe, confortável) sensação de um mero transmissor, uma quase vítima de um discurso indireto, que habita, molda a sua fala, e o submete a um circuito restrito, que o faz passar incessantemente da palavra de ordem à ordem silenciosa das coisas, e vice-versa.

Para se criar condições de que o sentido de um significante se abra para outras possibilidades de escrita e de leitura, torna-se necessário revogar, ainda que temporariamente, os regimes propagados, que condicionam a significação. A instauração de outro modo de operar a linguagem solicita 
o reconhecimento e o enfrentamento das condições sociais que determinam tais regimes de significação. Assim, não há como considerar a linguagem como algo fora do campo político, na medida em que um enunciado se concretiza na própria tensão que estabelece com os regimes estéticos em voga. Ou, como afirmam Deleuze e Guattari, "a linguagem é caso de política antes de ser caso de linguística" (1995, p. 97).

Não existe significância independente das significações dominantes nem subjetivação independente de uma ordem estabelecida de sujeição. Ambas dependem da natureza e da transmissão das palavras de ordem em um campo social dado. (Ibid., p. 17)

Para que o discurso se efetive como singularidade possível, e a voz recuse a soar como mera ressonância de um fragmento destacado do coro, é preciso fazer reverberar as pulsões que nos habitam e constituem, "trazer à luz esse agenciamento do inconsciente, selecionar as vozes sussurrantes, convocar as tribos e os idiomas secretos" (Ibid., p. 24) e deixar que nos atravessem de um lado a outro, de modo que se possa estabelecer uma tensão produtiva, subversiva com os regimes vigentes.

\title{
Percursos de uma percepção flutuante
}

\author{
A pequena suburbana \\ Naquela periferia. \\ Uma simples vira-lata \\ No fundo da Via Láctea. \\ Sem nome e sem dinastia \\ Se pinta como distinta. \\ E ainda pensa e pondera: \\ Ai quem me dera. Sei lá... \\ Uma atmosfera. \\ Tom Zé \& Caetano Veloso
}

Podemos encontrar no espetáculo Folias Galileu, estreado em 2013, no Galpão do Folias, na cidade de São Paulo, evidências de uma proposta artística que não se fixa em um ponto central, mas que se abre para os cantos, para o gesto insignificante, em que tudo pode ganhar sentido. Desprovida de um centro claramente definido, que poderia servir como guia para a leitura, 
"a compreensão se torna parcial, se contradiz e se interrompe, ela falha e retorna, vibra - e, dessa maneira, torna-se experiência" (LEHMANN, 2007, p. 145). O que sugere uma teatralidade que recusa a compreensão como fim determinado a ser atingido, que não quer deixar o ato de leitura limpidamente organizado e claramente apreensível.

Tal como a revolução científica deflagrada por Galileu Galilei que bagunça o nosso entendimento acerca das hierarquias do universo ao retirar a Terra de seu lugar central, classificando-a como um planeta qualquer, que passa a habitar a periferia da Via Láctea, a proposta estética do grupo paulistano Folias D’Arte convida-nos a experimentar essa instigante desorganização cosmogônica operada pelo astrônomo italiano. As cenas, criadas a partir da peça Vida de Galileu, de Bertolt Brecht, são apresentadas, ao mesmo tempo, nos mais diversos e inesperados espaços do galpão teatral do grupo. Estamos no espaço cênico, soltos e livres, passeando de um quadro para o outro, sem que qualquer ordenação das cenas precise ser respeitada. Para cada diferente percurso na visitação dos quadros, novas possibilidades de sentido; para cada grupo de espectadores, distintas leituras em potencial, configurando camadas singulares de significados a serem estabelecidas.

Durante a encenação, o sopro que acompanha o segredo de Andrea, discípulo de Galileu, que revela que "a terra se move", chega até os nossos ouvidos. Esse sopro, pouco a pouco, se faz vento, que arrasta e bagunça as nossas certezas, ao dispersar quaisquer impressões e expectativas iniciais de encontro com uma cena que ordenadamente nos revelará a figura emblemática do cientista italiano. Entramos e saímos do teatro sem encontrar o astrônomo, que não aparece em nenhuma das cenas, mas, ao mesmo tempo, nos deparamos com suas inquietações, nos encontramos na mesma condição de incerteza em que se viu Galileu e os demais personagens que nele acreditavam ou não. No mesmo estado incômodo e oscilante, somos colocados entre a potência de uma vontade revolucionária e a frustração ante a iminência de retorno da sempre e mesma acomodação conservadora.

Assim, vamos nos deslocando (e sendo deslocados) pelo espaço, nos deparando com elementos provocativos, instigantes, que solicitam de modo explícito a nossa atuação como espectador: uma fábula desfeita, que nos propõe certo desconcerto na relação com o ambiente; cenas que entram em 
fricção com as anteriores; grupos de espectadores que passeiam pelo galpão, caminhando de um quadro para o outro, se cruzam e se entreolham; a cacofonia que invade o espaço sonoro, produzida pelas vozes das cenas simultâneas, nos estimula a perceber, vez ou outra, palavras e frases significativas que invadem, de modo aleatório, as cenas que estamos acompanhando; uma encenação que se presentifica como coral, composta como justaposição de várias e distintas vozes e personas; um protagonista ausente, que parece inacabado ou que muda de configuração a cada encontro com outro personagem que se refere a ele de modo distinto.

Ao chegarmos ao teatro, recebemos estolas de nove cores diferentes e, trajando esses adereços comumente utilizados por clérigos, os nove grupos de espectadores partem em deriva pelo espaço cênico. No percurso pelo galpão do Folias, que cada conjunto de espectadores percorre em ordenação diferente, encontramos variadas cenas e personagens que trazem notícias de Galileu e das repercussões que sua teoria revolucionária provocou no período; das quais podemos destacar, entre outras: (a) dona Sarti, governanta de Galileu, em um cômodo da casa, mostra, ao mesmo tempo, sua admiração pela postura irreverente do patrão e o receio do que pode acontecer com ele e com Andrea, filho da governanta, que segue os mesmos rumos profissionais do astrônomo; (b) um padre matemático que, em cena bem-humorada, encerrado no banheiro, sofre com fortes e intermináveis dores de barriga, ante a desconfortável situação que Ihe foi conferida de julgamento e condenação do autor das novas descobertas científicas; (c) o menino Andrea, encantado com as inovações de Galileu, recebe os espectadores em seu pequeno quarto para explicar, de modo lúdico, o que significa habitar um planeta que se move; (d) o mesmo Andrea, cientista e já adulto, visita o velho amigo para cobrar satisfações, e resta à espera do mestre na antessala da casa, mostrando-se indignado pelo fato de Galileu ter renegado seus importantes achados científicos; (e) um clérigo, envolto em pesada fumaça e odor de incenso, apresenta para os espectadores, de maneira pausada e pretensamente amigável, o modo de utilização e a função litúrgica de variadas vestimentas e apetrechos utilizados pelos padres em rituais religiosos; $(f)$ uma senhora abastada, mãe de Ludovico, aluno particular de Galileu, revela seus temores quanto às perspectivas políticas e sociais das invenções do 
cientista, que vislumbra um universo desprovido de relações hierárquicas; (g) Virgínia, filha de Galileu, envolta por um imenso vestido de noiva, provido de véu interminável que ocupa toda a cena, lamenta o provável cancelamento de seu casamento com Ludovico, em face das repercussões ocasionadas pela condenação do pai; (h) Virgínia, em cena que acontece na rua e no bar em frente ao teatro, delicia-se com a recente e retumbante fama do pai, e pelo fato de ser facilmente reconhecida pelos passantes como a filha de Galileu; (i) dona Sarti, na cozinha da casa, se mostra tensa com o que pode ocorrer com seu patrão, ameaçado de ir para a fogueira, enquanto tempera um largo pedaço de carne crua; (j) um sacerdote cego, locado em um porão obscuro, à luz de velas, queima documentos, enquanto destila um ódio sussurrado ante a perspectiva revolucionária que se anuncia; (k) Federzoni, polidor das lentes do telescópio utilizado por Galileu, acolhe os espectadores em pequena e escura sala, e, enquanto trabalha, comenta, em linguagem incompreensível, os meandros de seu labor com as lentes; (I) um padre filósofo reflete sobre a impossibilidade e os incalculáveis prejuízos de qualquer tentativa de explicar a seus pais camponeses e religiosos sobre a nova configuração de um céu bagunçado e desertificado.

Cada espaço do galpão do Folias se assemelhava, na trajetória em busca de Galileu, a uma ilha de sentidos, em cada canto podíamos encontrar uma espécie de instalação, um sítio capaz de falar por si mesmo, de falar conosco. Espaços de intersecções e de subversões possíveis. Em proposição cênica assim elaborada, a significação de cada cena, cada personagem, cada elemento, e a relação desses com os demais, torna-se claramente definida pelas decisões que o espectador toma em seu trajeto de leitura, em função das escolhas que faz, das associações que estabelece entre as produções significantes com que se depara, por aquilo que opta em carregar como sentidos em potencial, e que continua sendo rearticulado por ele na sequência dos acontecimentos surgentes.

O que nos possibilita pensar que tal modo de produção artística suprime a relação entre sujeito e objeto que marcava a tradicional estética do drama, mesmo em chave moderna. Não se trata mais de um sujeito-espectador que se debruça sobre um objeto-cena na perspectiva de entendê-la, porém de uma relação experiencial, em que a obra não se constitui somente como algo 
que está em cena, mas também como aquilo que o espectador produz a partir do que lhe acontece. O espectador se vê convidado a experimentar esse modo de interação e passa a relacionar os elementos da escrita cênica a uma situação nele despertada, produzindo uma determinada condição de eficácia para a cena, que se efetiva a partir de sua relação com ela, que não pode mais ser realizada por meio da divisão entre sujeito e objeto. "Por conseguinte, o sentido não é mais algo a ser explicado, mas um efeito a ser experimentado" (ISER, 1996, p. 33). O espectador coloca-se em experiência, tornando-se sujeito e objeto no processo. Sujeito que cria, compreende, analisa, e objeto que é atravessado pela proposta artística, e, assim se torna objeto da própria observação, atento às suas expectativas, frustrações, memórias, hipóteses, antecipações, convicções e comportamentos.

Essa maleabilidade dos signos, ou mesmo a falta de constituição destes - o que se estabelece como proposição de jogo e pode ser tomado como incitamento à emancipação do espectador -, propõe um regime de sensibilidade distinto, que possibilita ao leitor tomar cada produção surgida no decorrer do processo, seja intencional ou furtiva - um gesto casual do ator, um barulho vindo de fora, um jorro imagético inesperado advindo das profundezas da memória, ou mesmo um afeto de difícil caracterização -, como significante legitimamente constituído, que pode ser integrado ao ato de leitura.

A partir dessa perspectiva, o percurso de leitura do texto cênico suscita no espectador, tornado participante, uma infinidade de sensações, imagens, sonoridades, lembradas e inventadas, e que são revistas, modificadas, recriadas no decorrer do próprio processo. Cada novo elemento de significação que surge no avançar da leitura, proposto intencionalmente ou não pelo artista - um personagem desconhecido, uma palavra dissonante, uma ação surpreendente, uma reação de alguém da plateia, um ruído inesperado -, estimula o espectador a revisitar o arsenal de lances perceptivos, mnemônicos e inventivos produzidos por ele até então, tecendo novas associações possíveis, outras possibilidades de análise.

Nesse processo, o espectador carrega algumas alternativas das provisórias produções simbólicas, que vai gerindo no decorrer do ato, e abandona outras, que perdem sentido ao serem relacionadas com os novos elementos cênicos que surgem ao longo do evento. De modo que qualquer interpretação 
final realizada pelo espectador nunca abarca os tantos lances forjados por ele no percurso, e mesmo as produções passageiras e descartadas no trajeto não podem ser desconsideradas em sua relevância, em seu potencial de sentidos e de efetivação estética.

\section{O performativo posto em debate}

Como integrantes do iNerTE1, tivemos a oportunidade de propor dois debates performativos a partir de Folias Galileu², buscando evidenciar o modo de produção do público em sua relação com o espetáculo, e enunciar, em ato coletivo, uma poética dos espectadores. O eixo investigativo que norteia os debates performativos realizados a partir de um espetáculo teatral diz respeito ao modo como as cenas apresentadas atingem cada um dos espectadores, apontando para a revelação de impressões que se configuram de maneira pessoal e intransferível no desenrolar do acontecimento artístico. $O$ espectador se percebe, desse modo, como um pesquisador, atento ao modo como performa enquanto realiza o próprio ato de leitura, tanto na relação com o espetáculo ao qual assistiu, quanto na observação de si mesmo, na maneira com que toma a si como objeto de análise, atento aos impactos e percursos da própria percepção.

Com os debates performativos, intentamos descortinar alguns desses elementos de leitura, ou chaves de pensamento que operam na relação que o espectador trava com a proposição artística, almejamos desvendar o mosaico de impressões que o coletivo de espectadores enuncia ao reverberar conjuntamente os impactos provocados pela encenação. Para isso, buscamos deixar claro, desde o início, que não estamos em busca de um debate tradicional que pretende deixar claro o que o espetáculo quis dizer. Não queremos, nem nos sentimos autorizados a estabelecer vetores de leitura ou mesmo explicar para o espectador aquilo que ele deveria entender. Estamos, ao contrário, buscando o modo com que o espetáculo atingiu, atravessou a cada um de nós. Ou

1 O iNerTE (Instável Núcleo de Estudos de Recepção Teatral) foi criado em 2004, junto ao Programa de Pós-Graduação em Artes Cênicas da USP (ver <http://www.eca.usp.br/ inerte>). Em 2016, o núcleo se transfere para Florianópolis, passando a atuar junto ao Programa de Pós-Graduação em Teatro da UDESC.

2 Os debates foram realizados em outubro de 2013 e junho de 2014. 
seja, nos importa menos a busca de responder a pergunta "o que isso quer dizer?" e mais a tentativa de enfrentar a questão "o que aconteceu comigo?".

Em Folias Galileu tivemos um espaço propício a essa pesquisa ${ }^{3}$. O espetáculo, organizado a partir da flutuação das cenas, colocava também em plena flutuação a nossa percepção, que, atenta às sutilezas, capturava lances inesperados e significativos, descobertos a cada instante do evento. Assim que abrimos o debate, perguntamos como os espectadores observaram uns aos outros; se alguém poderia narrar alguma imagem ou gesto significativo percebido nos demais espectadores durante o espetáculo. Uma participante ressaltou que, na cena do Padre - que acontecia no banheiro masculino do teatro, em que o personagem sofria com intensa diarreia enquanto lia as incômodas descobertas de Galileu -, como esta não podia ser vista, pois o Padre estava trancado em uma cabine do banheiro e os espectadores apenas ouviam suas falas e o som de suas necessidades fisiológicas, a cena, ou o que havia de visível nela, acontecia especialmente no rosto dos outros espectadores, que reagiam corporalmente às falas e sonoridades vindas de dentro da cabine. Essa espectadora ressaltou como isso era premente para que os espectadores observassem uns aos outros: "você não vê o ator, só vê os espectadores e suas reações.' Os gestos dos espectadores eram tomados como significantes que, a cada sessão, participavam de modo distinto e imprevisível da composição cênica.

Diante da mesma pergunta - acerca da observação dos demais espectadores -, outro participante observou, ao comentar também a cena do banheiro, que não existia qualquer odor desagradável no local, mas na reação dos espectadores sim. Era como se a percepção de cada um, em sua relação sensorial já experimentada em outros banheiros, cutucasse a sua memória fazendo surgir o cheiro inexistente. Em todos os presentes se tornava perceptível a clara expressão de desagrado.

Ainda acerca das reações e gestos significativos dos demais espectadores, ouvimos também um participante do debate comentar como as estolas, vestimentas comumente usadas por padres que eram utilizadas por cada um dos espectadores durante todo o espetáculo, abria sentidos em potencial.

3 Vídeo desse debate performativo está disponível em: <https://www.youtube.com/watch?$v=V C G E y c R 3 t G U>$. 
Receber e vestir a estola colorida, oferecida pelos artistas, já nos trazia um desafio, um enigma, uma provocação de como integrar aquele elemento à leitura do espetáculo. Todos os espectadores passeavam pelo galpão enquanto assistiam às cenas vestidos com estolas. Estaríamos posicionados como padres, convidados a analisar a validade das descobertas de Galileu? O modo com que cada espectador vestia a estola parecia significativo. Um dos participantes comentou como um outro, que estava todo trajado com roupa preta, que este se parecia com um padre ao vestir a estola. Como se a combinação daquela roupa preta com a estola vermelha compusesse um possível figurino, e aquele espectador pudesse ser percebido como um personagem, ainda que sem função claramente definida. Um personagem tão impactante quanto desnecessário; como um religioso que passeasse pelo teatro sem função definida, mas que poderia participar das injunções, associações e opções de leitura realizadas pelos demais espectadores.

O mesmo participante do debate relatou ainda que esse espectador vestido de preto trazia outra característica que Ihe parecia significativa: tinha os cabelos curtos e oxigenados. A roupa preta, a estola vermelha e o cabelo louro pintado fez que se lembrasse de outro espetáculo teatral a que tinha assistido, em que o ator tinha um figurino e um cabelo semelhantes. A peça que lhe ocorria era A trágica história do dr. Fausto, escrita no século XVI pelo dramaturgo inglês Christopher Marlowe, e o personagem que surgia da visão daquele espectador de cabelos louros era Mefistófeles, figura demoníaca a quem Fausto pede poder e conhecimento, oferecendo em troca a própria alma. As possibilidades de associação entre um espetáculo teatral e outro surgia como enigma a ser decifrado. Por que a memória de Fausto surgia agora durante a encenação de Galileu? Como relacionar Fausto com Galileu? Há relações possíveis a serem estabelecidas a partir da confrontação surgida de maneira aleatória entre os dois espetáculos? Será que o pacto que Fausto fez com Mefistófeles, oferecendo-Ihe em troca a própria alma, poderia ser relacionado com as agruras e a capitulação de Galileu ante as ameaças da Inquisição?

A produção dos atos engendrada pelo espectador foge ao controle total do artista, especialmente em manifestações marcadas por evidente caráter performativo. É nesse hiato entre o que é proposto e o que é produzido que se origina o potencial artístico da recepção. O artista e o espectador participam 
de um jogo, "jogo que sequer se iniciaria se o texto [a proposta artística] pretendesse ser algo mais do que uma regra de jogo" (ISER, 1999, p. 110). O prazer da leitura efetiva-se no momento em que nossa inventividade é acionada, em que nossa produtividade entra em jogo.

[A performatividade] resulta de um novo arranjo dos dados, que constituem propriamente um "lance." Este novo arranjo obtém-se, a maioria das vezes, pondo em conexão séries de dados tidos até então como independentes. Pode-se chamar imaginação a esta capacidade de articular juntamente o que não estava. (LYOTARD, 1989, p. 106)

Outros elementos de cena foram pouco a pouco sendo destacados pelos participantes, de modo que, a partir do "poema" proposto pelos artistas, outro "poema" se desenvolvia com fluidez e densidade. Entre as imagens trazidas à tona, vale destacar, como exemplo, a situação surgida da memória de um jovem participante que - vestido com um casaco-varal, cravejado de pregadores de roupas e carregado de distintas frases escritas pelo coletivo de espectadores - narrou o seguinte: certa vez, por ocasião de uma festa junina, esperava ansiosamente que um vestido ficasse pronto para que ele pudesse usar no dia em que o evento ocorreria em sua cidade. Ele usaria um vestido de noiva durante o casamento que ocorre tradicionalmente nessas comemorações, e isso o apavorava, por vestir-se de mulher em público, mas também o alegrava, pelo desafio de enfrentar os olhares e julgamentos dos outros, e realizar algo que tinha tanta vontade de fazer. A memória dessa situação ocorreu para o espectador enquanto assistia à cena em que Virgínia, a filha de Galileu, aparece costurando um enorme vestido de noiva e conta que seu pai, com suas ideias novas e desconcertantes acerca do universo, havia tornado seu casamento impossível.

O fato pessoal relatado pelo participante e a angústia de sua experiência pessoal ante aquela situação que irrompia agora em nosso debate, colocava em tensão dados reais com elementos ficcionais. A cena do espetáculo era interrompida por outra cena, aquela advinda da memória involuntária durante o processo de leitura. Ou, dito de outro modo, a imagem surgida da memória irrigava a imagem proposta pelo espetáculo. Pois, diante da imagem cênica provocativa, em jogo de linguagem que desestimula a mera decifração interpretativa, 
"o espectador, longe de buscar um sentido para a imagem, deixa-se levar por esta performatividade em ação. Ele performa" (FÉRAL, 2008, p. 202).

\section{Referências bibliográficas}

BAKHTIN, M. Estética da criação verbal. São Paulo: Martins Fontes, 1992.

BRITO, R. Experiência crítica. São Paulo: Cosac Naify, 2005.

CHKLOVSKI, V. L'art comme procédé. In: TODOROV, Tzvetan (Org.). Théorie de la littérature. Paris: Seuil, 2001.

DELEUZE, G.; GUATTARI, F. Mil platôs: capitalismo e esquizofrenia, v. 2. Rio de Janeiro: Editora 34, 1995.

DESGRANGES, F. A inversão da olhadela: alterações no ato do espectador teatral.

2. ed. São Paulo: Hucitec, 2017.

A pedagogia do espectador. 3. ed. São Paulo: Hucitec, 2015.

DESGRANGES, F.; SIMÕES, G. Folias Galileu: percursos de uma percepção flutuan-

te. Caderno do Folias, São Paulo, n. 15, 2015.

FÉRAL, J. Por uma poética da performatividade: o teatro performativo. Sala Preta,

São Paulo, n. 8, 2008. Disponível em: <http://dx.doi.org/10.11606/issn.2238-3867. v8i0p197-210>. Acesso em: 13 mar. 2017.

GUATTARI, F. Caosmose: um novo paradigma estético. São Paulo: Editora 34, 2012. ISER, W. O ato da leitura: uma teoria do efeito estético, v. 1. São Paulo: Editora 34, 1996.

O ato da leitura: uma teoria do efeito estético, v. 2. São Paulo: Editora 34, 1999.

JAUSS, H. R. A história da literatura como provocação à teoria literária. São Paulo: Ática, 1994.

LEHMANN, H.-T. Motivos para desejar uma arte da não-compreensão. Urdimento

- Revista de Estudos em Artes Cênicas, Florianópolis, n. 9, p. 141-152, 2007.

LYOTARD, J.-F. A condição pós-moderna. Lisboa: Gradiva, 1989.

RANCIÈRE, J. O espectador emancipado. São Paulo: WMF Martins Fontes, 2012.

SIMÕES, G. Veto ao modernismo no teatro brasileiro. São Paulo: Hucitec; Fapesp, 2010.

Recebido em 13/03/2017

Aprovado em 02/05/2017

Publicado em 17/07/2017 